\title{
Characteristics of Apposition in The Great Gatsby
}

\author{
Elena Seoane Posse \\ Universidad de Santiago de Compostela
}

\begin{abstract}
The aim of this paper is to study the syntactic and semantic characteristics of apposition as exemplified in The Great Gatsby, a novel written by F. Scott Fitzgerald in the 1920s, which, due to its narrator's tendency to poeticize reality and to detailed description, provides a good many examples of the use of apposition in all its varieties. In the pages that follow I first establish a set of definite criteria which define apposition and then I go on to illustrate these in the appositions found in the novel mentioned above. Finally I offer a pragmatic and stylistic explanation for the author's frequent use of appositions.
\end{abstract}

\section{Introduction}

A wide range of definitions of apposition can be found in the literature, so that in order to differentiate apposition from coordination and subordination, a set of definite criteria has first to be established. Authors in general have distinguished three types of criteria: syntactic, semantic and pragmatic. I shall therefore examine the criteria I shall be taking into account to consider a construction as apposition:

\section{Syntactic constraints:}

- The two units of apposition (U1 and $\mathrm{U} 2$ ) fulfil the same syntactic function with respect to the rest of the sentence.

- U1 and U2 may belong to the same or to different syntactic classes.

- U1 and U2 are juxtaposed or can be juxtaposed without forming an unacceptable sentence.

\section{Semantic constraint:}

- U1 and U2 are co-referential.

\section{Pragmatic constraint:}

- U2 must supply new information about U1. 
As far as the syntactic constraints are concerned, the requirement for an apposition to form a functional unit has been put forward by Hockett, Sopher, Burton-Roberts, Quirk et al. and Fuentes Rodríguez but, rather surprisingly, it is not taken into account by Meyer ("Apposition in English" and "Restrictive Apposition"). Both Meyer, Quirk et al. and Fuentes Rodriguez consider that $\mathrm{U} 1$ and $\mathrm{U} 2$ can belong to the same or to different form classes, while Hockett remarks that for a construction to be an apposition both its units must have the same form class. Curme and Jespersen base their definition on the formal criteria of $\mathrm{U} 1$ and $\mathrm{U} 2$ being obligatorily juxtaposed (a-position); on the other hand, Meyer and Quirk et al. remark that a construction can be appositive even if its units are not juxtaposed: they must only be able to be juxtaposed without yielding an unacceptable sentence.

The semantic constraint of co-referentiality is referred to by Hockett, Sopher, BurtonRoberts, Quirk et al. and Fuentes Rodríguez, while Meyer applies the term apposition to non-coreferential units, and Strawson remarks that most units in apposition are not referends and therefore cannot co-refer. Finally, it is from Meyer that I have incorporated the pragmatic constraint: U2 must supply new information about U1.

The most coherent criteria to define and characterize apposition are, from my point of view, those mentioned above, which cannot be assigned to any author in particular, but derive, as has just been seen, from various resources.

\subsection{The syntactic function of apposition}

As Meyer remarks in his article ("Apposition in British and American English"), appositions have functions associated mainly with those of noun phrases. The data in my corpus prove this, because, as Table 1 shows, 76 out of the 82 appositions in the corpus fulfil nominal functions, namely subject, direct object, subject complement and complement of preposition. The only non-nominal function appositions fulfil in the corpus is that of adverbial.

NOMINAL AND NON NOMINAL FUNCTION OF APPOSITION

(Table 1)

\begin{tabular}{lcr}
\hline TYPE OF FUNCTION & OCCURRENCES & PROPORTION \\
\hline Nominal & 76 & $92.6 \%$ \\
Non nominal & 6 & $7.3 \%$ \\
\hline Totals & 82 & $100 \%$ \\
\hline
\end{tabular}

Table 2 provides the breakdown of the functions fulfilled by the appositions in the corpus with respect to the overall sentence in which they are embedded. The following examples from the corpus illustrate these various functions of apposition in the corpus (appositive units underlined): 
(1) (subject): The sister, Catherine, was a slender, worldly girl of about thirty. ... (32)

(2) (c. of prep.): She was apalled by West Egg, this unprecedent place that Broadway had begotten upon a Long Island fishing village. . . (103)

(3) (direct object): And he knew that he had lost that part of it, the freshest and the best, forever. (146)

(4) (subject c.): This is a valley of ashes-a fantastic farm where ashes grow like wheat into ridges and hills and grotesque gardens. ... (26)

(5) (adverbial): No telephone message arrived, but the butler went without his sleep and waited for it until four o'clock-until long after there was anyone to give it to if it came. (153)

SYNTACTIC FUNCTION OF APPOSITION

(Table 2)

\begin{tabular}{lcr}
\hline \hline TYPE OF FUNCTION & OCCURRENCES & PROPORTION \\
\hline Subject & 31 & $37.8 \%$ \\
Complement of preposition & 23 & $28.04 \%$ \\
Direct object & 13 & $15.8 \%$ \\
Subject complement & 9 & $10.9 \%$ \\
Adverbial & 6 & $7.3 \%$ \\
\hline Totals & 82 & $100 \%$ \\
\hline \hline
\end{tabular}

As regards appositions with a subject function, these can be divided into two types: non-existential subject and existential subject, the latter being illustrated in example (6). The percentage is set out in Table 3:

(6) (existential subject): There was a slow, pleasant movement in the air, scarcely a wind, promising a cool, lovely day. (144)

\section{SUBJECT FUNCTION IN APPOSITION}

(Table 3)

\begin{tabular}{lcr}
\hline \hline TYPE OF SUBJECT FUNCTION & OCCURRENCES & PROPORTION \\
\hline Existential subject & 4 & $12.9 \%$ \\
Non-existential subject & 27 & $87 \%$ \\
\hline Totals & 31 & $37.8 \%$ \\
\hline
\end{tabular}

Finally, a last aspect worthy of mention is that appositions in the corpus with an adverbial function are only place or time adverbials, as Table 4 and examples (7) and (8) show:1 
ADVERBIAL FUNCTION IN APPOSTTION

(Table 4)

\begin{tabular}{lcr}
\hline TYPE OF ADVERBIAL & OCCURRENCES & PROPORTION \\
\hline Place & 4 & $66 \%$ \\
Time & 2 & $33.3 \%$ \\
\hline Totals & 6 & $7.3 \%$ \\
\hline
\end{tabular}

(7) (place): He did not know that it was already behind him, some where back in that vast obscurity beyond the city, where the dark fields of the republic rolled on under the night. (171)

(8) (time): I kept it always full of interesting people, night and day. (87)

\subsection{The principle of end-weight}

Meyer ("Apposition in British and American English") points out that the principle of endweight (as defined for instance in Quirk et al.) is intimately connected with apposition. This is true indeed, as can be demonstrated by means of the data in the corpus: $59.7 \%$ of the appositions in the corpus have functions associated with positions that promote endweight, namely complement of preposition, direct object, subject complement and existential subject, functions illustrated respectively in the examples below, in which the end-weight principle is explicit:

(9) (complement of preposition): I slunk off in the direction of the cocktail table-the only place in the garden where a single man could linger without looking purposeless and alone. (44)

(10) (direct object): And it was from Cody that he inherited money, a legacy of twentyfive thousand dollars. (97)

(11) (subject complement): At first I thought it was another party, a wild rout that had resolved itself into "hide-and-go-seek" or "sardines-in-the-box" with all the house thrown open to the game. (79)

(12) (existential subject): ... already there are wanderers, confident girls who weave here and there among the stouter and more stable, become for a sharp, joyous moment the centre of the group, and then, exited with triumph, glide on through the sea-change of faces and voices and colour under the constantly changing light. (42)

Moreover, even functions which do not promote end-weight are not normally located in preverbal position if they are fulfilled by an apposition. Thus, among the 31 cases of appositon having a non-existential subject (which does not promote end-weight), only 11 have a preverbal subject position. Appositions generally constitute a unit which is too long and complex to occupy initial position. In accordance with the principle of end-weight, the 
apposition is split and only U1 is left in preverbal position, while U2 is left stranded at the end of the sentence.

Sentences (13), (14) and (15) provide examples of appositional non-existential subjects in preverbal position, in preverbal and postverbal position, and in postverbal position respectively:

(13) (preverbal): Its vanished trees, the trees that had made way for Gatsby's house, had once pandered in whispers to the last and greatest of all human dreams. (171)

(14) (pre- and postverbal): We stayed there two days and two nights, a hundred and thirty men with sixteen Lewis guns, and when the infantry came up at last they found the insignia. ... (65)

(15) (postverbal): ... a limousine passed us, driven by a white chauffeur, in which sat three modish negroes, two bucks and a girl. (67)

Table 5 lists the different positions that this non-promoting end-weight function occupies in the appositions in the corpus. From these data we must conclude that the endweight principle affects appositive constructions in the great majority of cases, not only when they fulfil a function which promotes end-weight, but also with other functions, due to their length and complexity.

POSITION OF APPOSITIONS WITH NON EXISTENTIAL SUBJECT FUNCTION

(Table 5)

\begin{tabular}{lcr}
\hline \hline POSITION & OCCURRENCES & PROPORTION \\
\hline Preverbal & 11 & $40.7 \%$ \\
Pre- and postverbal & 11 & $40.7 \%$ \\
Postverbal & 5 & $18.5 \%$ \\
\hline Totals & 27 & $32.9 \%$ \\
\hline
\end{tabular}

\section{The syntactic class of apposition}

I have pointed out that most appositions in the corpus (92\%) fulfil a nominal function. Consequently, most appositions are of the type NP+NP. Table 6 lists the different syntactic forms of the units in apposition in the corpus.

In fact, there is a clear correspondence between syntactic function and syntactic class: the fact that most of appositions with an adverbial function belong to syntactic classes other than the nominal class proves this correspondence. Example (5), which we shall repeat here for convenience, and example (16) illustrate this point: 
(5) (PP+PP): No telephone message arrived, but the butler went without his sleep and waited for it until four o'clock-until long after there was anyone to give it to if it came. (153)

(16) $(\mathrm{PP}+\mathrm{PP})$ : I raised him out of nothing, right out of the gutter. (162)

SYNTACTIC CLASS OF UNITS IN APPOSITION

(Table 6)

\begin{tabular}{lcr}
\hline SYNTACTIC CLASS & OCCURRENCES & PROPORTION \\
\hline NP + NP & 74 & $90.2 \%$ \\
PP + PP & 3 & $3.6 \%$ \\
PP + NP & 2 & $2.4 \%$ \\
ADV. P + NP & 1 & $1.2 \%$ \\
NP + ADJ. P & 1 & $1.2 \%$ \\
ADJ. P + ADJ. P & 1 & $1.2 \%$ \\
\hline Totals & 82 & $100 \%$ \\
\hline \hline
\end{tabular}

Table 7 lists the statistical proportion of the different syntactic classes that fulfil an adverbial syntactic function. Among the instances of apposition of the nominal class, I have found three examples of reiterative apposition, sentences (17), (18) and (19). These are constructions where one of the appositives consists itself of two or more units which are themselves in apposition (see Quirk et al. 625-26).

SYNTACTIC CLASS OF APPOSITIONS WITH ADVERBIAL FUNCTION

(Table 7)

\begin{tabular}{lcr}
\hline SYNTACTIC CLASS & OCCURRENCES & PROPORTION \\
\hline PP + PP & 3 & $50 \%$ \\
PP + NP & 2 & $33 \%$ \\
ADV.P + NP & 1 & $16 \%$ \\
\hline Totals & 6 & $7.3 \%$ \\
\hline
\end{tabular}

(17) $[\mathrm{NP}+(\mathrm{NP}+\mathrm{NP})]$ : I felt it in others-poor young clerks who loitered in front of windows waiting until it was time for a solitary dinner-young clerks in the dusk, wasting the most poignant moments of night and life. (57)

(18) [NP+(NP+NP)]: Perhaps some unbelievable guest would arrive, a person infinitely rare and to be marvelled at, some radiant young girl who with one fresh glance at Gatsby, one moment of magical encounter, would blot out those five years of unwavering devotion. (105) 
(19) [NP+(NP+NP)]: I was promoted to be a major, and every Allied government gave me a decoration-even Montenegro, little Montenegro down on the Adriatic sea! (65)

Finally, I have observed that most units in apposition in the corpus (95.1\%) are of the same syntactic class. Only four appositive constructions in the corpus have units belonging to different syntactic classes: NP+ADJ.P; ADV:P+NP; and PP+NP (two instances).

\section{Juxtaposition of the units in apposition}

The third of the syntactic constraints on apposition I outlined in the introduction to this paper dealt with the position of U1 and U2 with respect to each other. As Meyer remarks ("Apposition in English" 116-17), for a construction to be apposition, U1 and U2 must be juxtaposed or must be able to be juxtaposed without affecting the acceptability of the sentence.

With regard to the frequency of juxtaposition in apposition, $80.4 \%$ of the appositions in the corpus have their units juxtaposed. The remaining $19.5 \%$ have their units unjuxtaposed, but they might be juxtaposed without making the resulting sentence unacceptable. Sentences (20) and (21) provide examples of juxtaposed and unjuxtaposed units in apposition respectively:

(20) The other car, the one going to New York, came to a rest.... (131)

(21) So we beat on, boats against the current, borne back ceaselessly into the past. (172)

Now, if we try to juxtapose the units in sentence (21), the resulting sentence is grammatically correct and equivalent to the primitive sentence:

(21a) So we, boats against the current, borne back ceaselessly into the past, beat on. (172)

There are various reasons why units in apposition do not appear juxtaposed, and they have been set out in Table 8 .

REASONS FOR NOT JUXTAPOSING UNITS IN APPOSITION

(Table 8)

\begin{tabular}{lcr}
\hline \hline FACTOR & OCCURRENCES & PROPORTION \\
\hline End focus and end-weight & 13 & $81.25 \%$ \\
Pronoun stress & 2 & $12.5 \%$ \\
Other & 1 & $6.25 \%$ \\
\hline Totals & 16 & $19.5 \%$ \\
\hline \hline
\end{tabular}


As Table 8 illustrates, there is one dominant factor for not juxtaposing the units in apposition: the principles of end-focus and end-weight, which can be seen at work in, for instance, sentence (18), repeated below for convenience:

(18) Perhaps some unbelievable guest would arrive, a person infinitely rare and to be marvelled at, some radiant young girl who with one fresh glance at Gatsby, one moment of magical encounter, would blot out those five years of unwavering devotion. (105)

In sentence (18) the juxtaposition of the units would have made the resulting sentence completely unbalanced, with a long, complex subject contrasting with the concise verbal predicate "would arrive" left stranded at the end. In addition, the resulting sentence would have lacked the emphasis and focalization the narrator meant to place on the second unit of the apposition.

End-focus and end-weight are generally difficult to separate, yet in some cases it is end-focus that is foremost, as in example (19), repeated below for convenience, whereas the reverse is true in (22):

(19) (end-focus): I was promoted to be a major, and every Allied government gave me a decoration-even Montenegro, little Montenegro down on the Adriatic sea! (65)

(22) (end-weight): Our procession of three cars reached the cemetery and stopped in a thick drizzle beside the gate-first a motor hearse, horribly black and wet, then Mr Gatz and the minister and me in the limousine, and a little later four or five servants and the postman from West Egg, in Gatsby's station wagon, all wet to the skin. (165)

Example (19) has the units in apposition unjuxtaposed in order to focalize the second unit by placing it at the end of the sentence. In this way, the proper noun "Montenegro" is highlighted in its context by means of three devices: the subjunct "even" which premodifies it, the formal feature of placing it between a dash and an exclamation mark, and its unjuxtaposed final position. In its turn, in example (22) the apposition contains a very long second unit, which describes in full detail the contents of the first. For this reason the apposition is split-despite its non-existential subject function-and the second unit is placed at the end of the sentence. In this way the narrator can avoid an unbalanced and difficult sentence.

The second reason for not juxtaposing units in apposition, as illustrated in Table 8 , is pronoun stress. By this I mean the fact that, when the first unit of an apposition is a pronoun, the second unit is not juxtaposed to it, in order to avoid placing too much stress on a pronoun beginning a sentence or clause. Only two instances of this type have been found:

(14) We stayed there two days and two nights, a hundred and thirty men with sixteen Lewis guns, and when the infantry came up at last they found the insignia ... (65)

(23) I went back to the drawing-room and thought for an instant that they were chance visitors, all these official people who suddenly filled it. (156) 
Finally, in just one example, quoted below as (24), the discontinuity of the two appositives is made necessary by the presence of the adverbial modifier "too." As can be seen in (24a), juxtaposition would bring about a change in the scope of the adverbial, and so would substantially alter the meaning of the sentence:

(24) I had heard some story of her too, a criticah unpleasant story, but what it was I had forgotten long ago. (23)

(24a) I had heard some story of her, a critical, unpleasant story too, but what it was I had forgotten long ago.

\section{The semantics of apposition}

The literature on apposition provides us with various semantic classifications. Among the most outstanding are those put forward by Quirk et al. (628-38) and Meyer ("Apposition in British and American English" 13-17), and it is this latter I have mainly adopted in the following pages. Meyer distinguishes three major types of semantic relationship, depending on the degree of specificity of the second appositive unit with respect to the first: more specific, less specific and equally specific. Within these three major semantic types, he further differentiates between the following semantic classes of apposition:

\section{More specific:}

- Identification: the second appositive element specifies the identity of the first one.

- Appellation: the second appositive element specifies the name of the first, it names it.

- Particularization: the second appositive unit specifies or focusses on some part or aspect of the first unit.

- Exemplification: the second appositive unit provides an example of the first one.

2. Less specific:

- Characterization: the second appositive unit attributes some characteristic to the first unit.

3. Equally specific:

- Paraphrase: the second appositive unit paraphrases the first one.

- Reorientation: the second appositive unit restates what has been said in the first one.

- Self-correction: the second appositive units corrects what has been said in the first one.

Considering first the three major types of semantic relationship holding between the first and the second appositive units, I must admit that the data in the corpus do not coincide with those of Meyer, who classified $25 \%$ of the appositions he studied as equally specific, while only $16 \%$ of the total were less specific. On the contrary, as Table 9 indicates, less specific appositions are more frequent than equally specific ones in The Great Gatsby. 
But my results do coincide with Meyer's in that the second unit of most appositions is more specific than the first, and among these the most frequent semantic relationship is that of identification. Examples (1), (19) (repeated below for convenience), (25) and (26) illustrate with examples from the corpus the various subtypes of more specific apposition, while Table 10 provides their number and their statistical proportion:

(25) (identification): Gravely the men turn in at a house-the wrong house. (167)

(1) (appellation): The sister, Catherine, was a slender, worldly girl of about thirty .... (32)

(19) (particularization): I was promoted to be a major, and every Allied government gave me a decoration-even Montenegro, little Montenegro down on the Adriatic sea! (65)

(26) (exemplification): After that I lived like a young rajah in all the capitals of Europe-Paris, Venice, Rome.... (64)

DEGREE OF SPECIFICITY IN THE SECOND UNIT OF APPOSITTON

(Table 9)

\begin{tabular}{lcr}
\hline \hline DEGREE OF SPECIFICITY & OCCURRENCES & PROPORTION \\
\hline More specific & 59 & $71.9 \%$ \\
Less specific & 14 & $17 \%$ \\
Equally specific & 9 & $10.9 \%$ \\
\hline Totals & 82 & $100 \%$ \\
\hline
\end{tabular}

MORE SPECIFIC APPOSITIONS

(Table 10)

\begin{tabular}{lcr}
\hline SEMANTIC CLASS & OCCURRENCES & PROPORTION \\
\hline Identification & 45 & $76.2 \%$ \\
Appellation & 10 & $16.9 \%$ \\
Particularization & 2 & $3.3 \%$ \\
Exemplification & 2 & $3.3 \%$ \\
\hline Totals & 59 & $71.9 \%$ \\
\hline
\end{tabular}

I have not found any instance of self-correction apposition in The Great Gatsby. Among the other equally specific types of apposition, the most frequent are reorientation or re-statement appositions, as Table 11 shows. Equally specific constructions are illustrated in examples (8), which I will repeat again for convenience, and (27):

(8) (paraphrase): I kept it always full of interesting people, night and day. (87) 
(27) (reorientation): I graduated from New Haven in 1915, just a quarter of a century after my father, and a little later I participated in that delayed Teutonic migration. . . (9)

Finally, example (5) shows the use of apposition with the purpose of characterization, i.e. U2 is less specific:

(5) No telephone message arrived, but the butler went without his sleep and waited for it until four o'clock-until long after there was anyone to give it to if it came. (153)

EQUALLY SPECIFIC APPOSITIONS

(Table 11)

\begin{tabular}{lcr}
\hline \hline SEMANTIC CLASS & OCCURRENCES & PROPORTION \\
\hline Paraphrase & 4 & $44.4 \%$ \\
Reorientation & 5 & $55.5 \%$ \\
Self-correction & 0 & $0 \%$ \\
\hline Totals & 9 & $10.9 \%$ \\
\hline \hline
\end{tabular}

\section{Use of apposition in the corpus}

After this brief survey of the syntactic and semantic characteristics of apposition in the corpus, I must now turn to consider the reasons that led the author to use so many appositions in such a few pages. The great majority of the appositions are found in the narrator's idiolect, on which I shall concentrate now. They constitute a total of 63 appositions out of the 82 in the corpus. The remaining 19 appositions correspond to the characters' dialogues, and I shall be dealing with them later on.

The narrator of Gatsby's story is Nick, who is, at the same time, one of the characters involved in the story itself. The novel, therefore, is unfolded to the reader from Nick's point of view. Indeed, what we finally obtain from the novel is not Gatsby's story-as it might seem at first sight-but how that story affected Nick and came to change his personality and his way of viewing the reality surrounding him. In the following pages I shall set forth the crucial function apposition fulfils as an expressive device in this double role of Nick in The Great Gatsby: [1] Nick as the narrator and [2] Nick as a character.

[1] Although Nick as a character involved in the story is very much upset over it and accordingly his view of it is highly partial, nevertheless, when he assumes the role of narrator, he pretends to be telling the story in a very objective and exhaustive way. To attain such objectivity he uses several devices: he presents himself as a reflective, rational narrator who would never be deceived by false appearances; he tries to prove that Gatsby's story did not even interest him, when we know that it affected him very deeply; and, what is more interesting for us, he tries to give every detail of what happened, placing himself as an objective camera eye that sees and reports everything without changing or selecting 
any data. It is such purpose that apposition effectively serves, because it contains a second unit whose function is to provide new information about the particular entity Nick is referring to (the first unit of apposition).

The kind of information U2 supplies is generally more specific than that contained in U1 in 71\% of all cases (see Table 9), and it is so for two reasons. First, because it is Nick's aim to give a specific, fully detailed version of the story, so as to pretend that he is an objective narrator. Examples (28) and (29) illustrate this stylistic function of the narrator's appositions:

(28) Finally we came to Gatsby's own apartment, a bedroom and a bath, and an Adam's study, where we sat and drank a glass of some Chartreuse he took from a cupboard in the wall. (88)

(29) They were a party of three on horseback-Tom and a man named Sloane and a pretty woman in a brown riding habit, who had been there previously. (98)

The second reason for Nick's frequent use of apposition is that, as the only narrator of the story, it is his role to introduce us to every character, situation and scene. This accounts for the fact that, among more specific appositions, he favours in particular the identification and appellation types, which constitute a device especially useful to provide whatever information a narrator considers relevant for the reader. Sentences (30) and (31) are examples of this presentation of characters by means of the identification and appellation kinds of apposition respectively:

(30) (identification): It belonged to Demaine, the oil man. (13)

(31) (appellation): The young Greek, Michaelis, who runs the coffee joint beside the ashheaps was the principal witness at the inquest. (129)

[2] At the very beginnig of the novel, Nick presents himself as a learned man, and we can see it in his language, which is full of latinisms, complex subordinate sentences and a rich and wide vocabulary. This upbringing leads him to take note of every commonplace detail that is new to him, and raise it to the category of the extraordinary and even magic. The narrator uses two devices to do this: on the one hand, he makes comparisons, introduced by "as" or "like." On the other, he uses the less and equally specific types of apposition. Sentences (4), (21) (repeated below) and (32) are a good example of this poetic vision of reality:

(4) This is a valley of ashes-a fantastic farm where ashes grow like wheat into ridges and hills and grotesque gardens.... (26)

(21) So we beat on, boats against the current, borne back ceaselessly into the past. (172)

(32) Gatsby believed in the green light, the orgastic future that year by year recedes before us. (171)

I shall finally consider the appositions I have found in the characters' dialogues. Gatsby uses 11 appositions, all of which contain a second unit providing more specific information about the first, as example (33) illustrates: 
(33) After that I lived like a young rajah in all the capitals of Europe-Paris, Venice, Rome-collecting jewels, chiefly rubies, hunting big game, painting a little .... (64)

Tom Buchanan uses 3 appositions, Mr Wolfshiem 1, and Daisy and Jordan 2 appositions each. Their use, in a general sense, serves the purpose of providing new information about $\mathrm{U} 1$, with the aim of a better understanding between the speakers. For instance there is a passage in which Tom Buchanan tries to indicate to Nick the location of the place in which they are to meet. As Nick is new in town, Tom must specify where the place in question is, and he does so by means of an apposition:

(34) You follow me to the south side of Central Park, in front of the Plaza. (120)

There is a very peculiar character in the novel who never speaks to the point: it is Daisy Buchanan. And her emptiness of mind is amazingly reflected in the two appositions she uses: their second unit does not provide new information, they just repeat or emphasize in a futile way what she has previously said:

(35) You remind me of a-of $a$ rose, an absolute rose. (19)

(36) That's what I get for marrying a brute of a man-a great, big, hulking physical specimen of $a . \ldots(17)$

\section{Conclusions}

In this paper I have outlined the syntactic characteristics of apposition, basing my investigation on data derived from a written corpus. The conclusions I have drawn from the research can be summed up as follows:

1) Syntactic function: appositions tend to have a nominal function, in particular as subject or as complement of a preposition.

2) Principle of end-weight: most appositions function in positions that promote endweight; and among those which do not have that kind of end-weight promoting function, very few instances of apposition are located in preverbal position.

3) Syntactic class: the great majority of appositions contain units which belong to the same syntactic class, and most are of the class NP. Few cases were found of reiterative appositions.

4) Juxtaposition of units: most appositions have their units juxtaposed. The most common factor for not juxtaposing the units in apposition is the search for end-focus and end-weight.

5) The semantics of apposition: most appositions have a second unit which serves to specify-especially identify - the semantic contents in the first unit.

6) Stylistic factors: Scott Fitzgerald uses appositions mainly in the narrator's speech, with two purposes: that of providing the reader with every detail of the story, and that of making him share the poetic vision of his narrator. 


\section{Notes}

1. An element such as the apposition in example (7) is analised by some grammarians as a complement, because it is an essential constituent of the sentence. For the analysis of adverbials, however, I follow Quirk et al.'s position, as described in their Comprehensive Grammar (51-52): "It is worth pointing out that different degrees of centrality can be observed not only in different elements of clause structure, but also in different subcategories of the same element. Thus the adverbial category has been described as the most peripheral, but it is in fact a heterogeneus category, within which there are relatively central and relatively peripheral types of adverbial. In examples 2.13 [1-7], most of the adverbials are both mobile and optional: it is possible, for example, to omit the adverbial usually in [2] (My mother enjoys parties very much) as well as to change its position . . . But there are, as we just have seen in [2c], some adverbials which cannot readily be moved from their position in a given clause, and there are even adverbials which are obligatory, such as the place adverbials in the garden in example 2.13 [4] and upstairs in 2.13 [7]:

I have been in the garden all the time since lunch. [4]

You must put all the toys upstairs immediately. [7]

Contrast:

*I have been all the time since lunch. [4a]

*You must put all the toys immediately. [7a]"

\section{Works Cited}

Burton-Roberts, N. “Nominal apposition.” Foundations of Language 13 (1975): 391-419. Curme, G. O. Syntax. New York: Acdemic Press, 1931.

Fuentes Rodríguez, Catalina. "De nuevo sobre la aposición." Verba 16 (1989): 215-36.

Haugen, E. “On Resolving the Close Apposition.” American Speech 28 (1953): 165-70.

Hockett, Charles. "Attribution and Apposition." American Speech 30 (1955): 99-102.

Jespersen, O. Modern English Grammar on Historical Principles. London: Allen and Unwin, 1961.

Koktová, E. “Apposition as a Pragmatic Phenomenon in a Functional Description." UEA Papers in Linguistics (1985): 39-79.

Lee, D. W. “Close Apposition: An Unresolved Pattern.” American Speech 27 (1952): 268-75.

Matthews, P. Syntax. Cambridge: Cambridge UP, 1981.

Meyer, C. "Apposition in British and American English." Forthcoming.

. "Apposition in English.” Journal of English Linguistics 20 (1987): 101-21.

. "Restrictive Apposition: An Indeterminate Category." English Studies 70 (1989): 147-66.

Quirk, R., et al. A Comprehensive Grammar of the English Language. London: Longman, 1985.

Scott Fitzgerald, F. The Great Gatsby. Harmondsworth: Penguin, 1987.

Sopher, H. “Apposition.” English Studies 52 (1971): 401-12.

Strawson, P. F. Introduction to Logical Theory. London: Methuen, 1952. 